\title{
The Association between Body Mass Index and Body Fat in College Students 大學生身體質量指數與體脂肪之關連性分析
}

\author{
Chang-Hung HUNG \\ Office of Physical Education, \\ National Chin-Yi University of Technology, TAIWAN \\ 洪彰鴻 \\ 台灣國立勤益科技大學體育室
}

\begin{abstract}
This study explored the association between BMI and body fat assessed by bioelectrical impedance analysis (BIA) in college students. Cross-sectional studies of 2,531 college students were measured. BIA was used to quantify body fat mass (BFM), percentage of body mass $(\% \mathrm{BF})$ and visceral fat area (VFA). Significant correlations between BMI and BFM, \%BF, VFA were fund, respectively $(\mathrm{r}=0.923,0.836,0.912$ in male, $\mathrm{p}<0.001 ; \mathrm{r}=0.920,0.741,0.920$ in female, $\mathrm{p}<0.001$ ). Regression analysis revealed that $85.3 \%, 69.9 \%$, and $83.1 \%$ of the variance for BFM, \%BF, and VFA could be explained by BMI in male students ( $\mathrm{p}<0.001$ ); and $84.7 \%$, 54.9\%, and $84.6 \%$ of the variance for BFM, \%BF, VFA could be explained by BMI in female students ( $\mathrm{p}<0.001$ ). BFM and VFA were highly associated with BMI in college students, suggesting that BMI serves as a good surrogate marker for obesity in college students aged 18-24 years. However, a significantly medium correlation existed in BMI and $\% \mathrm{BF}$, which may be a limitation for BMI, when used to study risk factors for cardiovascular or metabolic diseases.
\end{abstract}

Key words: body mass index, bioelectrical impedance analysis, body fat, college students

\section{摘 要}

本研究主要探討大學生身體質量指數 (BMI) 與體脂肪之關連性。總共有2,531位大學生進行測量。以生物電阻分析 (BIA) 身體脂肪量 (BFM)、身體脂肪百分比 (\%BF) 與內藏脂肪 $(\mathrm{VFA})$ ，結果顯示：BMI與BFM、\%BF、VFA均達顯著相關 $(\mathrm{p}<0.001)$ 。本研究結果顯示大學生族群BMI與BFM、VFA有高度的關連性。因此, 建議BMI可以做為18一24歲大學生族群評估肥 胖之替代指標。然而, 由於BMI與 $\% B F$ 僅存著中等的關連性, 如果以BMI作為研究心血管或代謝疾病的危險因子, 可能會成為研 究之限制。

關鍵詞：身體質量指數、生物電阻分析、體脂肪、大學生

\section{Introduction}

Obesity is the most important nutritional disease in the developed countries of the world, where its prevalence has increased particularly rapidly over the last two decades (WHO, 2000). In Taiwan, the prevalence of overweight and obese students increased significantly between 1991 and 2003 (Liou1, Huang, \& Chou, 2009). Obesity is known to have serious adverse metabolic and cardiovascular consequences (Miller et al., 2004). Obesity is the condition of increased body weight caused by excessive accumulation of fat. Measuring percent body fat $(\% \mathrm{BF})$ is an ideal way to 
diagnose obesity (Morimoto et al., 2007). A variety of methods are available to measure body fatness and body thinness (Mei et al., 2002). Commonly used techniques for the accurate estimation of body fatness include underwater weighing, dual-energy X-ray absorptiometry (DXA), bioelectrical impedance analysis (BIA). The most frequently used tools in public health evaluations and clinical screening are anthropometric-based measurements such as skinfold thickness or circumference measurements or body mass index (BMI). BMI is the one most commonly recommended and widely used for classifying overweight and obesity in adults and has also been recommended for screening overweight and obesity in adolescents (Mei et al., 2002). BMI has been used extensively as a surrogate measurement for body fat in epidemiological studies when estimating risk for cardiovascular disease and all-cause mortality (Katzmarzyk et al., 2003). The popularity of this approach is due to its simplicity and the relatively good correlations with fatness.

However, BMI does not account for the wide variation in body fat distribution, and has considerable limitations in predicting intra-abdominal fat accumulation (Deurenberg \& Yap, 1999), and it may misclassify those with high muscle mass into overweight or obese (Völgyi et al., 2008). BMI is an indirect measure of body fat compared with more direct approaches such as bioelectrical impedance analysis (BIA). BIA is one of the most popular methods used to estimate body fat (BF) in clinical practice. BIA is available in single (SFBIA) and multi-frequency (MF-BIA) models, and presents several advantages such as non-invasiveness, portability and relatively inexpensive (Pietrobelli, Rubiano, St-Onge, \& Heymsfield, 2004; Shafer, Siders, Johnson, \& Lukaski, 2009). BIA provide detailed information not only on fat mass (FM) but also on estimates of lean mass, total body water (TBW), and fat distribution within the whole body and segmental lengths (Salmi, 2003). There are known ethnical differences in the relation between BMI and body fatness (Deurenberg et al., 2003; Morimoto et al., 2007; Navder et al., 2009). Several studies have shown that body composition and risks associated with obesity can differ in Asians depending on the geographic location or nationality of the sample studied (Stevens, Kimberly, Truesdale, Katz, \& Cai, 2008). Very few data have been conducted the correlation between BMI and body fat mass $(\mathrm{BFM})$, percentage body fat $(\% \mathrm{BF})$, visceral fat area (VFA) assessed by BIA (InBody 720) in college students. Therefore, the purpose of this study was to evaluate the relationship between BMI and BFM, \%BF, VFA. We wished to determine whether BMI measures could be used as surrogate markers to estimate adipose tissue in college students aged 18-24 years.

\section{Method}

\section{Subjects}

A total of 2,531 (1,648 male and 885 female) college students aged 18-24 years were recruited for this cross-sectional study in central Taiwan in 2008.

\section{Anthropometric Measures}

Height was measured to the nearest $0.5 \mathrm{~cm}$ using the stadiometer with subjects standing erect without shoes. BMI was calculated as weight (in kilograms) divided by height (in meters) squared.

\section{Bioelectrical Impedance Analysis}

Body composition measurements of subjects were carried out with bioelectrical impedance analysis (InBody 720 Body Composition Analyzer, Biospace, Seoul, Korea) by trained personnel. InBody 720 uses an 8-point tactile electrode system that measures the total and segmental impedance and phase angle of alternating electric current at six different frequencies. It was used according to the manufacturer's instructions. Bedogni et al. (2002) pointed out that the InBody 720 device provided precise and accurate estimates of body composition. Subjects took a rest for over $20 \mathrm{~min}$ before measurement. Then subjects took off excess clothing, shoes, and socks, stood on the four foot-electrodes on the instrument's platform and held the two palm-and-thumb electrodes with the arms not touching the torso. With these electrodes, microprocessorcontrolled switches and impedance analyzer were operated and segmental resistance was measured at six frequencies (1 kHz, $5 \mathrm{kHz}, 50 \mathrm{kHz}, 250 \mathrm{kHz}, 500 \mathrm{kHz}$, and 1 $\mathrm{MHz})$ and reactance at three specific frequencies $(5 \mathrm{kHz}$, $50 \mathrm{kHz}$, and $250 \mathrm{kHz}$ ). Thus, a set of 30 segmental resistances was measured for each individual. Each subject's height and age were entered, and the body composition data were calculated by the device's software and immediately printed on the paper obtained from the manufacturer. 


\section{Statistical Analysis}

Means and standard deviations (SD) were calculated for all variables. Continuous variables were tested using the t-test. Pearson correlation coefficient was used to examine the relations between $\mathrm{BMI}$ and $\mathrm{BFM}, \% \mathrm{BF}$, and AFM measured by InBody 720 Body Composition Analyzer. Linear regression analysis was performed with $\mathrm{BFM}, \% \mathrm{BF}$, and VFA as dependent variables and BMI as independent variable. All analyses were performed using SPSS for window. Statistical significance was set at a level of $\mathrm{p}<0.05$.

\section{Results}

A total of 2,531 college students (1,646 males, 855 females) aged 18-24 years were included in this study. Age, anthropometric and InBody 720 measurements data are shown in Table 1 . The mean age of the students was $19.74 \pm 1.37$ years $(19.80 \pm 1.45$ years in male; $19.63 \pm 1.21$ years in female). The mean BMI of the students was $22.07 \pm 3.70 \mathrm{~kg} / \mathrm{m}^{2} \quad\left(22.64 \pm 3.79 \mathrm{~kg} / \mathrm{m}^{2}\right.$ in male $21.00 \pm 3.26 \mathrm{~kg} / \mathrm{m}^{2}$ in female). The mean BFM was $14.17 \pm 7.21 \mathrm{~kg}(13.17 \pm 7.61 \mathrm{~kg}$ in male; $16.01 \pm 5.98 \mathrm{~kg}$ in female). The mean $\% \mathrm{BF}$ was
$22.23 \pm 8.53 \%(18.58 \pm 7.29 \%$ in male, $29.02 \pm 6.21 \%$ in female). The mean VFA was $47.81 \pm 27.6 \mathrm{~cm}^{2}\left(51.71 \pm 29.67 \mathrm{~cm}^{2}\right.$ in male; $40.56 \pm 21.49 \mathrm{~cm}^{2}$ in female). Variables including height, weight, BMI, and VFA were significantly $(\mathrm{p}<0.001)$ higher in male than in female. Whereas, BFM and \%BF were significantly $(\mathrm{p}<0.001)$ higher in female than in male.

Table 2 shows the Pearson correlation coefficients between BMI measures and InBody 720 data, and with the corresponding scattergram for $\mathrm{BFM}, \% \mathrm{BF}$, and VFA in Figure 1, 2, 3, respectively. Highly significant and positively correlations between BMI versus BFM, \%BF, and VFA were fund in male $(\mathrm{r}=0.923,0.836,0.912$, respectively, $\mathrm{p}<0.001)$ and highly significant and positively correlations between BMI versus BFM and VFA were fund in male $(r=0.920,0.920$, respectively, $\mathrm{p}<0.001)$. Whereas, medium significant correlation between BMI and $\% \mathrm{BF}$ was fund in female.

Regression analysis revealed that $85.3 \%, 69.9 \%$, and $83.1 \%$ of the variance for BFM, \%BF, and VFA could be explained by BMI in male students $(\mathrm{p}<0.001)$; and $84.7 \%$, $54.9 \%$, and $84.6 \%$ of the variance for $\mathrm{BFM}, \% \mathrm{BF}$, and VFA could be explained by BMI in female students $(\mathrm{p}<0.001)$. Summary of regression analysis presented in Table 3.

Table 1. Age, Anthropometric and InBody 720 measurements Data for Subjects.

\begin{tabular}{|c|c|c|c|c|}
\hline \multirow[t]{2}{*}{ Variable } & \multirow{2}{*}{$\frac{\text { All, } n=2,531}{\text { Mean } \pm \text { SD }}$} & \multirow{2}{*}{$\frac{\text { Male, } n=1,646}{\text { Mean } \pm \mathrm{SD}}$} & \multicolumn{2}{|l|}{ Female, $n=855$} \\
\hline & & & Mean \pm SD & t-test \\
\hline Age (years) & $19.74 \pm 1.37$ & $19.80 \pm 1.45$ & $19.63 \pm 1.21$ & $3.11^{* *}$ \\
\hline \multicolumn{5}{|l|}{ Anthropometric } \\
\hline Heigt $(\mathrm{cm})$ & $168.18 \pm 8.06$ & $172.47 \pm 5.62$ & $160.20 \pm 5.39$ & $53.08^{* * *}$ \\
\hline Weight (kg) & $62.70 \pm 12.84$ & $67.40 \pm 12.04$ & $53.96 \pm 9.21$ & $31.34^{* * *}$ \\
\hline $\operatorname{BMI}\left(\mathrm{kg} / \mathrm{m}^{2}\right)$ & $22.07 \pm 3.70$ & $22.64 \pm 3.79$ & $21.00 \pm 3.26$ & $11.40^{* * *}$ \\
\hline \multicolumn{5}{|l|}{ InBody 720} \\
\hline BFM (kg) & $14.17 \pm 7.21$ & $13.17 \pm 7.61$ & $16.01 \pm 5.98$ & $-10.33^{* * *}$ \\
\hline$\% \mathrm{BF}(\%)$ & $22.23 \pm 8.53$ & $18.58 \pm 7.29$ & $29.02 \pm 6.21$ & $-37.91^{* * *}$ \\
\hline VFA (cm2) & $47.81 \pm 27.61$ & $51.71 \pm 29.67$ & $40.56 \pm 21.49$ & $10.85^{* * *}$ \\
\hline
\end{tabular}

Abbreviations: BMI, body mass index; BFM, body fat mass; \%BF, percent body fat; VFA, visceral fat mass;

** significant difference $\mathrm{p}<0.01, * * * \quad \mathrm{p}<0.001$. 
Table 2. Pearson Correlations between BMI and InBody 720 Data.

\begin{tabular}{llll}
\hline Variable & All, $\mathrm{n}=2,531$ & Male, $\mathrm{n}=1,646$ & Female, $\mathrm{n}=855$ \\
\hline BFM $(\mathrm{kg})$ & $0.845^{* * * *}$ & $0.923^{* * * *}$ & $0.920^{* * * *}$ \\
\%BF $(\%)$ & $0.511^{* * * * * * * * *}$ & $0.836^{* * * *}$ & $0.741^{* * * *}$ \\
VFA $\left(\mathrm{cm}^{2}\right)$ & $0.915^{* * * * *}$ & $0.912^{* * * *}$ & $0.920^{* * * *}$
\end{tabular}

Abbreviations: BMI, body mass index; BFM, body fat mass; \%BF, percent body fat; VFA, visceral fat mass *** significant difference $\mathrm{p}<0.001$.

Table 3. Summary of Regression Analysis of BMI with InBody 720 Data.

\begin{tabular}{|c|c|c|c|c|c|c|}
\hline Variable & & SE of Beta & $\beta$ & $\mathrm{t}$ & $\mathrm{R}^{2}$ & $\mathrm{~F}$ \\
\hline \multirow[t]{2}{*}{ All } & $\mathrm{BFM}(\mathrm{kg})$ & 0.021 & 0.845 & $79.54^{* * * *}$ & 0.714 & $6322^{* * *}$ \\
\hline & $\% \mathrm{BF}(\%)$ & 0.039 & 0.519 & $30.58^{* * *}$ & 0.269 & $931^{* * * *}$ \\
\hline VFA & $\left(\mathrm{cm}^{2}\right)$ & 0.060 & 0.915 & $113.96^{* * * *}$ & 0.837 & 12986 \\
\hline \multirow[t]{3}{*}{ Male } & $\mathrm{BFM}(\mathrm{kg})$ & 0.019 & 0.923 & $97.54^{* * *}$ & 0.853 & $9541^{* * * *}$ \\
\hline & $\% \mathrm{BF}(\%)$ & 0.026 & 0.836 & $61.84^{* * *}$ & 0.699 & $3823^{* * *}$ \\
\hline & VFA $\left(\mathrm{cm}^{2}\right)$ & 0.079 & 0.912 & $90.09^{* * * *}$ & 0.831 & $8115^{* * * *}$ \\
\hline \multirow[t]{3}{*}{ Female } & $\mathrm{BFM}(\mathrm{kg})$ & 0.024 & 0.920 & $69.97^{* * *}$ & 0.847 & $4896^{* * *}$ \\
\hline & $\% \mathrm{BF}(\%)$ & 0.043 & 0.741 & $32.83^{* * *}$ & 0.549 & $1077^{* * *}$ \\
\hline & VFA $\left(\mathrm{cm}^{2}\right)$ & 0.087 & 0.920 & $69.81^{* * *}$ & 0.846 & $4874^{* * *}$ \\
\hline
\end{tabular}

Dependent variable: body fat mass (BFM), percent body fat (\%BF), visceral fat mass (VFA), Independent variable: body mass index (BMI)

*** statistically significant $\mathrm{p}<0.001$.

Figure 1. Body mass index (BMI) vs. Body fat mass (BFM).
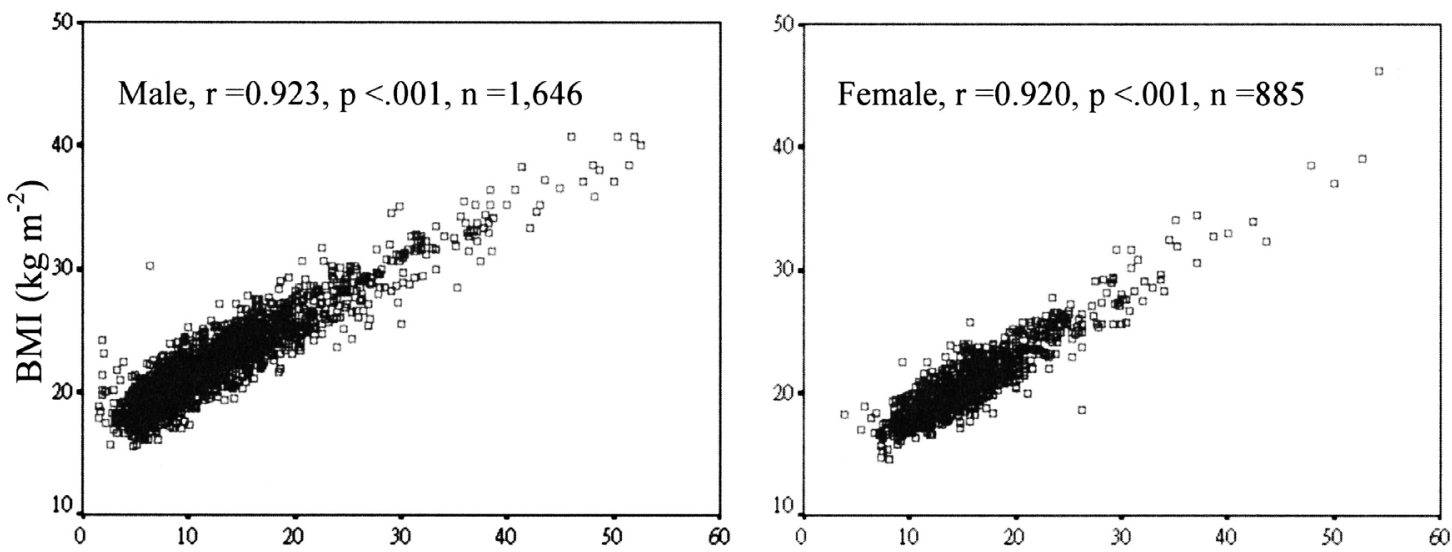

Body fat mass $(\mathrm{kg})$ 
Figure 2. Body mass index (BMI) vs. Percent body fat (\%BF).
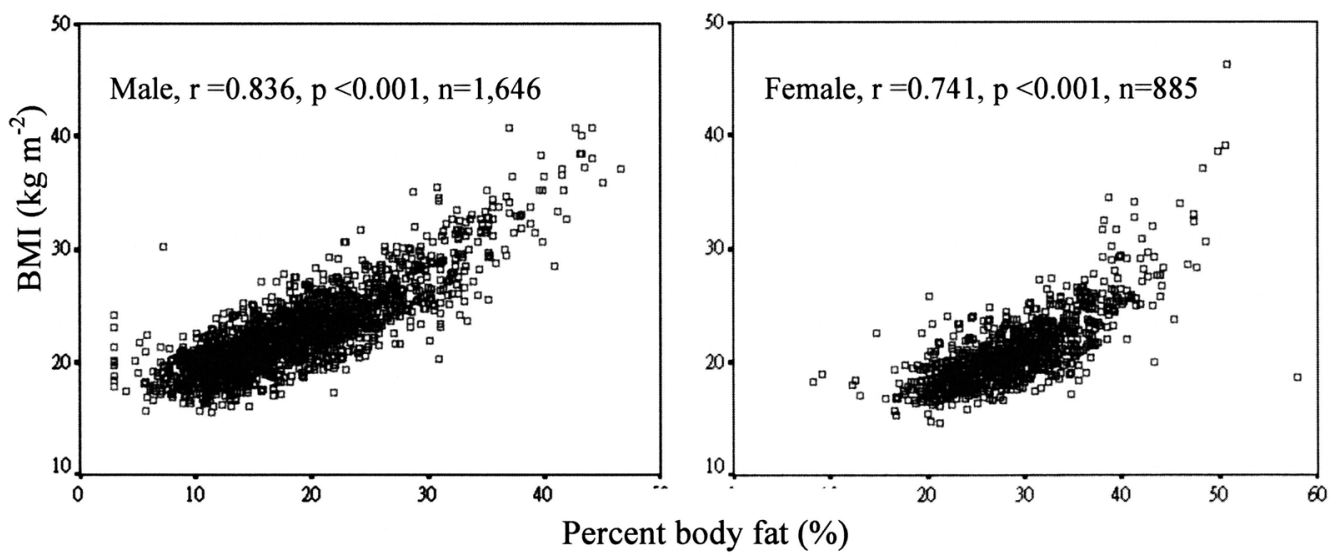

Figure 3. Body mass index (BMI) vs. Visceral fat area (VFA).
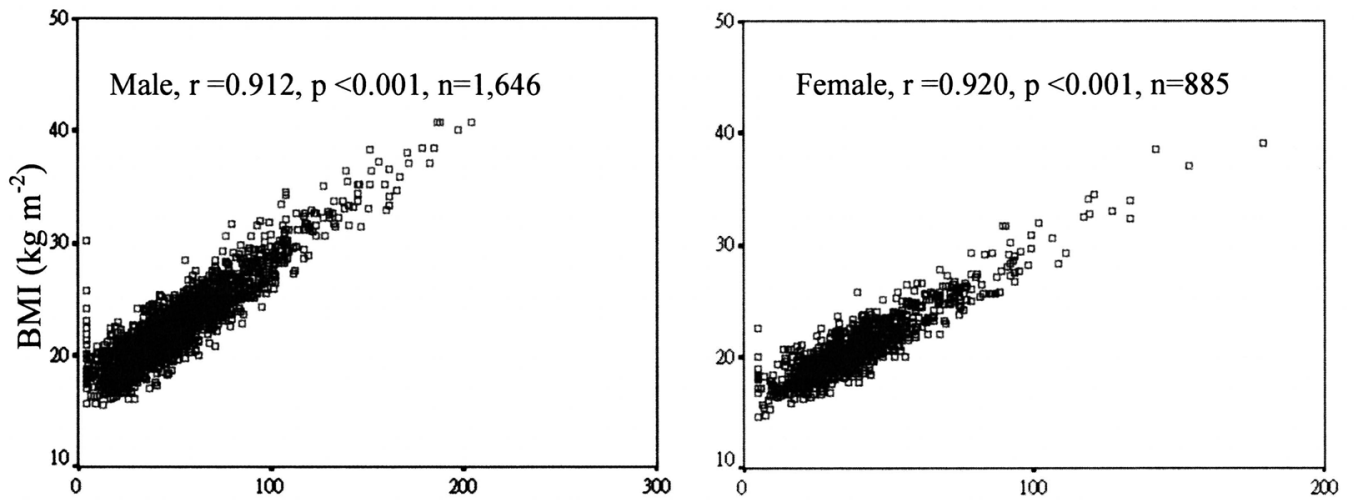

Visceral fat area $\left(\mathrm{cm}^{2}\right)$

\section{Discussion}

Objective measures of adiposity and fat distribution often are not feasible in large studies. BIA is a practical and non-invasive method to assess human body composition, and BMI is used by the World Health Organization to define severity of overweight and obesity across populations (WHO, 2004). In this study, significant relationships were detected between BMI and $\mathrm{BFM}, \% \mathrm{BF}$, and VFA, quantified by the InBody 720 technique. This indicates that BMI serves as a good surrogate measurement for body fat in college students in Taiwan, both for males and females regardless of gender differences in body composition. However, a medium correlation existed for BMI and \%BF especially in female students, which may be a limitation when BMI is used to study risk factors for disease in epidemiological studies of college students this age. Our finding that BMI was highly related to BFM, VFA, and medium related to $\% \mathrm{BF}$ derived from InBody 720 body composition analyzer. However, there are large sex differences in body fat mass in prepubertal children (Arfai et al., 2002; Denker et al., 2007; Garnett et al., 2004). In the present study, we also fund sex differences in BFM, VAF, and \%BF among college students. The possible explanation for differences is partly due to genetic differences in body composition, as well as to differences in food intake and the patterns of physical activity.

Height and body mass based measurements are the most common tools for assessing obesity status because of their simplicity and low cost. BMI has become the standard as a reliable indicator of overweight and obesity. Our data provide additional support for the use of BMI 
in assessing overweight and obesity in Taiwan adolescents aged 18-24 years. However, this only applies to the validity of BMI as an indicator of BFM and VFA, since significantly medium correlation existed between BMI and $\% \mathrm{BF}$.

The purpose of the present study was to evaluate the correlation between BMI and various body fat measurements, not to establish reference values for healthy college students. The main strength of this study was the use of InBody 720 to quantify the amount of BFM, $\mathrm{VAF}$, and $\% \mathrm{BF}$ in college students. To our knowledge, this is the first study that compares the relationship between BMI and BFM, VFA, \%BF among college students in Taiwan. Our study indicates that BMI serves as a good surrogate for BFM and VFA in college students aged 1824 years in Taiwan. The practical implication of this finding is the suggestion that perhaps measurement of waist circumference or waist to hip ratio is needed in addition to BMI, if epidemiological BMI-data are to be used to study prevalence or secular trends of risk factors for cardiovascular or metabolic disease.

\section{Conclusion}

In conclusion, BFM and VFA were highly associated with BMI in the college students in Taiwan, suggesting that BMI serves as a good surrogate marker for obesity in college students aged 18-24 years. However, a significantly medium correlation existed in BMI and \%BF, which may be a limitation for BMI, when used to study risk factors for cardiovascular or metabolic diseases.

\section{Reference}

Arfai, K., Pitukcheewanont, P. D., Goran, M. I., Tavare, C. J., Heller, L., \& Gilsanz, V. (2002). Bone, muscle, and fat: sex-related differences in prepubertal children. Radiology, 224, 338-344.

Bedogni, G., Malavolti, M., Severi, S., Poli, M., Mussi, C., Fantuzzi, A. L., \& Battistini, N. (2002). Accuracy of an eight-point tactile-electrode impedance method in the assessment of total body water. European Journal of Clinical Nutrition, 56, 1143-1148.

Bose, K. (2001). The interaction of waist-hip ratio and Conicity index with subcutaneous adiposity in two ethnic groups: native British and migrant Pakistani men. Anthropologischer Anzeiger, 59, 275-282.
Dencker, M., Thorsson, O., Linden, C., Wollmer, P., Andersen L. B., \& Karlsson, M. K. (2007). BMI and objectively measured body fat and body fat distribution in prepubertal children. Clinical Physiology and Functional Imaging, 27, 12-16.

Deurenberg, P., Deurenberg-Yap, M., Foo, L. F., Schmidt, G., \& Wang, J. (2003). Differences in body composition between Singapore Chinese, Beijing Chinese and Dutch children. European Journal of Clinical Nutrition, 57, 405-409.

Deurenberg, P., Yap, M. (1999). The assessment of obesity: methods for measuring body fat and global prevalence of obesity. Bailliere Clinical Endocrinol Metabolism, 13, 1-11.

Garnett, S. P., Hogler, W., Blades, B., Baur, L. A., Peat, J., Lee, J., \& Cowell, C. T. (2004). Relation between hormones and body composition, including bone, in prepubertal children. American Journal of Clinical Nutrition, 80, 966-972.

Katzmarzyk, P. T., Janssen, I., \& Ardern, C. I. (2003) Physical inactivity, excess adiposity and premature mortality. Obesity Reviews, 4, 257-290.

Liou, T. H., Huang, Y. C., \& Chou, P. (2009). Prevalence and secular trends in overweight and obese Taiwanese children and adolescents in 1991-2003. Annals of Human Biology, 36(2), 176-185.

Mei, Z., Grummer-Strawn, L. M., Pietrobelli, A., Goulding, A., Goran, M. I., \& Dietz, W. H. (2002). Validity of body mass index compared with other body composition screening indexes for the assessment of body fatness in children and adolescents. American Journal of Clinical Nutrition, 75(6), 978-985.

Miller, J., Rosenbloom, A., \& Silverstein, J. (2004). Childhood obesity. Journal of Clinical Endocrinol Metabolism, 89, 4211-4218.

Morimoto, A., Nishimura, R., Sano, H., Matsudaira, T., Miyashita, Y., Shirasawa, T., Koide, S., Takahashi E., \& Tajima, N. (2007). Gender differences in the relationship between percent body fat (\%BF) and body mass index (BMI) in Japanese children. Diabetes Research and Clinical Practice, 78, 123 125 
Navder, K. P., He, Q., Zhang, X., He, S., Gong, L., Sun, Y., Deckelbaum, R. J., Thornton, J., \& Gallagher, D. (2009). Relationship between body mass index and adiposity in prepubertal children: ethnic and geographic comparisons between New York City and Jinan City (China). Journal of Applied Physiology, 107, 488-493.

Pietrobelli, A., Rubiano, F., St-Onge, M. P., \& Heymsfield, S. (2004). New bioimpedance analysis system: improved phenotyping with whole-body analysis. European Journal of Clinical Nutrition, 58, 1479-1484.

Salmi, J. A. (2003). Body composition assessment with segmental multifrequency bioimpedance method. Journal of Sports Science and Medicine, 2(Suppl 3), 1-29.

Shafer, K. J., Siders, W. A., Johnson, L. K., \& Lukaski, H. C. (2009). Validity of segmental multiple-frequency bioelectrical impedance analysis to estimate body composition of adults across a range of body mass index. Nutrition, 25, 25-32.

Stevens, J., Truesdale, K. P., Katz, E. G., \& Cai, J. (2008). Impact of body mass index on incident hypertension and diabetes in chinese asians, american whites, and american blacks. American Journal of Epidemiology, 167, 1365-1374.
Völgyi, E., Tylavsky, F. A., Lyytikäinen, A., Suominen, H., Alén, M., \& Cheng, S. (2008). Assessing body composition with DXA and bioimpedance: effects of obesity, physical activity, and age. Obesity, 16, 700705.

World Health Organization. (2000). Obesity: preventing and managing the global epidemic. Report of a WHO consultation, World Health Organization Technical Report Series, 894, 1-253.

World Health Organization expert consultation. (2004). Appropriate body mass index for Asian populations and its implications for policy and intervention strategies. Lancet, 363, 157-163.

\section{Correspondence}

Chang-Hung HUNG

Office of Physical Education

National Chin-Yi University of Technology

No.35, Lane 215, Section 1, Chung-Shan Road,

Taiping City, Taichung, 411, TAIWAN.

E-mail: hongjh@ncut.edu.tw

TEL: 886-4-23924505 ext.8329 